\title{
Aprendendo Sobre Vírus a Partir de uma Proposta de Atividades Baseada nos Três Momentos Pedagógicos e no Enfoque CTSA
}

\section{Learning About Virus from an Activity Proposal Based on the Three Pedagogical Moments and the CTSA Approach}

\author{
Rosa Shizue Abe*a; Priscila Caroza Frasson Costa ${ }^{\mathrm{b}}$; Lucken Bueno Lucas ${ }^{\mathrm{b}}$

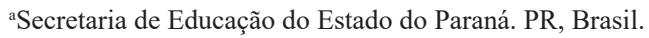

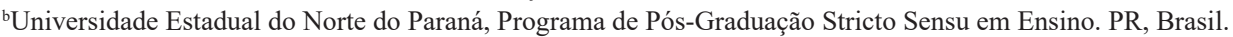 \\ *E-mail: rosacontardi@yahoo.com.br \\ Recebido em: 04/02/19; Aceito em: 09/08/19
}

\begin{abstract}
Resumo
Este trabalho, de cunho qualitativo, apresenta os resultados da aplicação de uma sequência de atividades sobre o tema vírus, estruturada na abordagem metodológica dos Três Momentos Pedagógicos e na perspectiva CTSA. Os participantes foram alunos do $7^{\circ}$ ano do Ensino Fundamental (anos finais) na disciplina de Ciências. Os dados compreenderam respostas dadas pelos discentes a avaliações diagnósticas (questionários inicial e final) da sequência, analisados por meio dos encaminhamentos da Análise Textual Discursiva. Como resultado, três categorias prévias foram efetivadas, sendo essas: noções distantes em relação à Microbiologia recente, noções incompletas em relação à Microbiologia recente e noções próximas à Microbiologia recente. As análises mostraram que as respostas dos alunos nas atividades finais da sequência apresentaram maior relação com os conhecimentos recentes da Microbiologia para o caso dos vírus, evidenciando as contribuições e pertinência do trabalho desenvolvido.
\end{abstract}

Palavras-chaves: Educação Científica. Contextualização do Conhecimento Escolar. Ensino Fundamental - Anos Finais.

\begin{abstract}
This qualitative work presents the results of the application of a sequence of activities on the theme virus, structured on the methodological approach of the Three Pedagogical Moments and the CTSA perspective. The participants were the 7th year students of Elementary School (final years), in the Science subject. The data comprised responses given by the students to diagnostic evaluations (initial and final questionnaires) of the sequence analyzed through the referrals of Discursive Textual Analysis. As results, three previous categories were implemented, namely: Distant notions in relation to recent Microbiology, Incomplete notions in relation to recent Microbiology, and Close notions in relation to recent Microbiology. The analyses showed that the students' responses to the final activities of the sequence were more related to recent knowledge of Microbiology in the case of viruses, demonstrating the contributions and relevance of the work developed.
\end{abstract}

Keywords: Scientific Education. School Knowledge Contextualization. Elementary School - Final Years.

\section{Introdução}

O tema vírus foi abordado nesta pesquisa em função de questionamentos de alunos acerca das campanhas de vacinação divulgadas pela mídia. $\mathrm{O}$ assunto é tratado como conteúdo específico do $7^{\circ}$ ano do Ensino Fundamental (anos finais) no Estado do Paraná, na disciplina de Ciências.

De fato, os meios de comunicação constantemente veiculam campanhas de vacinação, a fim de sensibilizar as pessoas sobre a necessidade da prevenção das doenças contagiosas. Entre essas se destacam alguns tipos de infecções virais, como: as gripes, pela facilidade de transmissão dos agentes patógenos. Em situações específicas, a instituição escolar se apresenta como um espaço importante para que se consiga atingir um grande número de vacinados, como no caso do vírus HPV (Papilomavírus humano).

Nesse contexto, é comum que os alunos adentrem a sala de aula com dúvidas em busca de esclarecimentos para questões como: por que tenho que me vacinar? Do que são feitas as vacinas? Vírus e bactérias são a mesma coisa? As vacinas curam os doentes?

Segundo Medeiros (2007), tanto a televisão quanto a escola são os principais meios de disseminação de temas científicos atuais. Sendo assim, concorda-se com a ideia de que a escola precisa trabalhar pela socialização do conhecimento, uma vez que tal função pode atingir, sobremaneira, os alunos das classes menos favorecidas, tendo por meio dela a oportunidade de acessar o mundo letrado, os diferentes campos do conhecimento, a arte e a reflexão (PARANÁ, 2008).

Em outras palavras, não basta que os alunos se imunizem embalados pelas campanhas de vacinação, mas que também se interessem, conheçam e questionem os conhecimentos científicos e tecnológicos envolvidos nesse processo. Assim, com o objetivo de contribuir para educação científica de alunos do Ensino Fundamental, no âmbito da disciplina de Ciências, investiga-se e se sistematiza uma sequência de atividades para o ensino do conteúdo vírus.

Para que a proposta pudesse estar pedagogicamente organizada, pautou-se em referenciais do enfoque Ciência, Tecnologia, Sociedade e Ambiente (CTSA) e em estudos 
sobre a abordagem dos Três Momentos Pedagógicos (3MP), como subsídios teórico-metodológicos desta intervenção. Essa composição possibilitou oferecer uma resposta para a questão norteadora: uma sequência de atividades pautada no enfoque CTSA e organizada segundo a abordagem dos 3MP pode favorecer a aprendizagem do conteúdo 'vírus' no âmbito do Ensino Fundamental - anos finais? A seguir, apresenta-se o arcabouço teórico utilizado no desenvolvimento da pesquisa.

Segundo noções recentes do campo da Microbiologia, os vírus são agentes patogênicos de bactérias, de animais e de plantas. O termo vírus em latim significa veneno, pois de acordo com Trabulsi e Alterthum (2015), antes do advento do microscópio eletrônico se acreditava que muitas doenças eram causadas por veneno. Aliás, a exatidão do tamanho diminuto dessas partículas só foi possível graças a esse aparelho de visualização. Os vírus estão classificados entre os menores agentes infecciosos já descritos, medindo entre 12 a 400 ๆm. As bactérias, em contrapartida, medem em torno de $1000 \eta \mathrm{m}$ (Staphylococcus).

Em função de sua estruturação simples, essas entidades não apresentam capacidade de crescimento autônomo. Sua replicação está condicionada ao uso da maquinaria celular de seres vivos, parasitando-os. Em muitos casos, ao infectar um organismo hospedeiro, o sistema imune do parasitado estimula a produção de anticorpos, inativando o invasor. A aplicação de vacinas está associada justamente a essa resposta imune do hospedeiro, a fim de combater as infecções virais.

A primeira vacina para humanos foi desenvolvida por Edward Jenner (Berkeley, 1749 - 1823), que atuou no controle da varíola (TRABULSI; ALTERTHUM, 2015). Em termos gerais, as vacinas são compostas de vírus atenuados que ao serem introduzidos em um organismo são reconhecidos por seus anticorpos, deixando-o imunizado contra o ataque de partículas não atenuadas do mesmo tipo.

Tortora, Funke e Case (2012) acrescem que desde a década de 1920 há experimentos com indução proposital de infecções virais no combate de tumores. Para eles, esse enfrentamento pode ser feito por meio de vírus específicos que, seletivamente, destruam células cancerosas, ou possam ser modificados geneticamente, a fim de infectá-las, também objetivando sua destruição.

No âmbito do ensino de Ciências, documentos oficiais como os que norteiam o trabalho pedagógico das disciplinas da Educação Básica do Estado do Paraná (Diretrizes Curriculares da Educação Básica - DCE) sugerem que o professor promova a contextualização do conhecimento a partir de relações conceituais, interdisciplinares e sócio históricas contextuais

A literatura da área de Ensino tem mostrado que ao contextualizar o ensino das disciplinas escolares com assuntos do cotidiano do aprendiz, há evidências da promoção de uma aprendizagem efetiva e com significados (KATO; KAWASAKI, 2011; DELIZOICOV; ANGOTTI; PERNAMBUCO, 2009).
Cabe evidenciar, ainda, que o tema vírus é controverso. Muito se discute sobre a aceitação ou não de que sejam formas simples de vida, por exemplo. Um tema é considerado controverso, quando não há consenso de opiniões, gerando polêmicas sobre assuntos carentes de evidências científicas, como no caso dos transgênicos, da nanotecnologia, entre outros (ZUIN; FREITAS, 2007; TOMA, 2009).

Ao abordar um tema controverso, em sala de aula, o professor poderá proporcionar momentos de reflexão, levando os alunos a perceberem que não há verdades irrefutáveis na ciência e que essa não é neutra, mas apresenta controvérsias. Como afirmam Silva e Carvalho (2007), os temas controversos possibilitam afastamento dos conceitos de harmonia, de verdade absoluta, de totalidade, de determinismo, do universo mecânico e de neutralidade, normalmente presentes no discurso científico.

Segundo Trivelato e Silva (2012), a incorporação de questões científicas controversas, como a Biotecnologia pelos professores nas aulas de Ciências se fundamenta em duas alegações principais: I) motivar seus alunos para compreenderem assuntos áridos e complexos, mas que aos olhos dos estudantes são importantes e requerem conhecimento, por se tratarem de temas, que afetam individual ou socialmente suas vidas; II) a possibilidade da integração e diálogo entre o professor e os alunos, no ouvir e respeitar as opiniões e pontos de vistas distintos.

Considerando a proposta de ensino na interface do assunto vírus, a partir do enfoque CTSA, especificamente a Biotecnologia, opta-se por uma abordagem de enxerto (PALACIOS et al., 2007) nas aulas de Ciências, ou seja, pelo emergir do contexto social dos aprendizes (vírus/vacinas) e incorporação na disciplina de elementos que pudessem levar os alunos à compreensão das pesquisas biotecnológicas contemporâneas acerca da utilização dos vírus em favor dos seres humanos (tema controverso).

Mais uma vez se recorre às pesquisadoras Trivelato e Silva (2012) quanto à dificuldade inerente de aprofundamento das questões técnicas relacionadas a esses assuntos, o que não seria possível no Ensino Básico", mas que na percepção de Krasilchik (2005), a análise de fenômenos biotecnológicos serve para diminuir a divisão entre a escola e o mundo em que os estudantes vivem, ao constatarem as relações entre a pesquisa científica e a produção industrial ou a tecnologia usada tradicionalmente em sua comunidade.

Sendo assim, para além da tradicional aula expositiva apoiada restritamente no livro didático (sem fazer juízo de valor negativo sobre esse tipo de aula) se propõe uma abordagem de ensino organizada nos Três Momentos Pedagógicos, assumindo a contextualização como princípio norteador desta proposta.

Os Três Momentos Pedagógicos recebem essa denominação por apresentarem três ensejos que perfazem o trabalho pedagógico do professor na condução de suas 
aulas, juntamente aos alunos. Muenche e Delizoicov (2014) esclarecem que essa abordagem foi proposta inicialmente por Delizoicov $(1982 ; 1983)$ ao sugerir a transposição da concepção de Paulo Freire para a educação formal.

Aliado a essas três fases objetiva-se com os $3 \mathrm{MP}$ uma proposição didática não somente do conhecimento a respeito dos vírus per se, mas a compreensão da não neutralidade da ciência, sua relação e interferência na sociedade e no ambiente por meio de suas tecnologias, ou seja, na perspectiva CTSA.

A instituição escolar ao estabelecer conexões da cultura científica com o cotidiano social dos alunos almeja a compreensão crítica do progresso e da influência da ciência no mundo em que se vive, nas instâncias sociais, políticas e econômicas, pois o conhecimento científico se constrói em relação intrínseca com a sociedade (TRIVELATO; SILVA, 2011).

\section{Material e Métodos}

Esta pesquisa apresenta caráter qualitativo segundo os pressupostos teóricos de Bogdan e Biklen (1994), que levam em conta a compreensão dos comportamentos a partir da perspectiva dos sujeitos da investigação e do ambiente social no qual estão inseridos.

Inicialmente se realizou uma revisão bibliográfica em documentos oficiais do Estado do Paraná voltados ao ensino de Ciências, em livros técnicos do Ensino Superior, que tratam dos vírus (Microbiologia), em literatura sobre fundamentos e métodos do ensino de Ciências na abordagem dos 3MP, além de artigos que versassem sobre a relação CTSA vinculados ao tema vírus. Empreendeu-se, também, consulta em veículos midiáticos para seleção de vídeos e textos informativos sobre biotecnologia e vírus, para serem inseridos nas atividades da sequência.

Após a estruturação das atividades a proposta foi apresentada e revisada por um docente do Ensino Superior, que pesquisa abordagens metodológicas de ensino na área de Ciências Naturais. Depois, com as devidas correções, a sequência de atividades foi implementada em uma turma composta por 22 alunos, que cursavam o $7^{\circ}$ ano do Ensino Fundamental (anos finais) de uma escola pública da região Norte do Estado do Paraná. A aplicação transcorreu em um total de seis horas/aulas, no $1^{\circ}$ semestre de 2018 , sendo a professora da turma uma das autoras deste artigo.

Antes da implementação da sequência foram esclarecidos os pais ou responsáveis (em reunião ordinária já agendada pela escola), a equipe pedagógica da escola e os próprios alunos, sendo explicados, assinados e recolhidos termos de consentimento livre e esclarecido (pais ou responsáveis) e termos de assentimento (alunos).

Para este artigo, os instrumentos de coleta de dados foram avaliações diagnósticas, compostas por questões abertas, realizadas no primeiro e no terceiro momento pedagógico da sequência de atividades. As respostas dos alunos foram analisadas segundo os encaminhamentos da Análise Discursiva
Textual (ATD) de Moraes e Galiazzi (2011). Primeiramente, os registros escritos dos aprendizes foram desmontados em segmentos textuais, analisados e reunidos em categorias por afinidade semântica, com a intenção de que surgissem novas compreensões desse conteúdo textual.

As categorias prévias estabelecidas pelos autores com base no referencial teórico da pesquisa, foram: I) noções próximas à Microbiologia recente; II) noções incompletas em relação à Microbiologia recente; III) noções distantes segundo a Microbiologia recente.

Os alunos foram codificados nos símbolos alfanuméricos A1, A2, A3, A4... e assim por diante. Já as avaliações foram representadas pelos símbolos Q1(questionário inicial) e Q2 (questionário final).

\section{Resultados e Discussão}

Para a análise dos resultados foram selecionadas as avaliações de seis alunos (entre os 22 participantes) a partir dos critérios de "diversidade" e "saturação". A diversidade é defendida por Guerra (2004, p. 40) como a pluralidade de concepções de uma coletividade, que pertence ao mesmo local, ou seja, busca-se analisar os questionários de alunos diversos (diferentes gêneros, idades, provenientes de zona urbana e rural, entre outros) para sustentar que eles representassem em diversidade a turma envolvida na implementação da proposta.

Quanto à saturação, Pires (1997, p.157) sustenta-a como uma generalização representativa dos resultados obtidos do grupo analisado (22 alunos do $7^{\circ}$ ano), indicando o momento em que o pesquisador deve parar a recolha dos dados no instante em que esses se tornam repetitivos, ou seja, em função da quantidade de material e das categorias prévias, não mais seja necessário sistematizar subcategorias ou categorias emergentes.

As categorias preestabelecidas foram efetivadas, porém segmentadas em subcategorias. Assim, são trazidas nos Quadros 1,2 e 3 as transcrições das respostas dos questionários 1 (aplicado no primeiro momento pedagógico) e 2 (aplicado no terceiro momento pedagógico), bem como a análise e entendimento de tais dados.

Quadro 1 - Categorias efetivadas

Categoria I - Noções distantes segundo a Microbiologia recente

Subcategoria: noções Vírus é uma doença que se espalha. do que seja vírus

Subcategoria: $\quad$ Não sei qual deles é o menor, os comparação quanto ao tamanho de vírus e bactérias (A2Q1)

Vírus é uma coisa ruim que se espalha. (A5Q1)

Um tipo de bactéria que causa vírus ou a bactéria. (A1Q1) A bactéria é menor do que os vírus. (A4, A5Q1) 


\begin{tabular}{|l|l|}
\hline $\begin{array}{l}\text { Subcategoria: } \\
\text { constituição estrutural } \\
\text { básica dos vírus }\end{array}$ & $\begin{array}{l}\text { Os vírus são formados de água ou de } \\
\text { uma única célula. (A1Q1) } \\
\text { Os vírus são formados de todas as } \\
\text { coisas ruins, daí eles começam a se } \\
\text { juntar. (A4Q1) } \\
\text { Os vírus são formados por células. } \\
\text { (A3, A5, A6Q1) } \\
\text { Não sei do que são formados os } \\
\text { vírus. (A2Q1) }\end{array}$ \\
\hline $\begin{array}{l}\text { Subcategoria: } \\
\text { ambientes dos vírus }\end{array}$ & $\begin{array}{l}\text { Os vírus podem ser encontrados } \\
\text { perto de sujeiras. (A1, A2Q1) }\end{array}$ \\
\hline $\begin{array}{l}\text { Subcategoria: meios de } \\
\text { combate aos vírus }\end{array}$ & $\begin{array}{l}\text { A maneira de combater os vírus é } \\
\text { tomando chá e remédio. (A1Q1) } \\
\text { Tomando remédios. (A3Q1) }\end{array}$ \\
\hline $\begin{array}{l}\text { Subcategoria: uso } \\
\text { benéfico dos vírus pelo } \\
\text { ser humano }\end{array}$ & $\begin{array}{l}\text { Os vírus podem ser usados pelo ser } \\
\text { humano para fazer veneno para rato. } \\
\text { (A1Q1) } \\
\text { Não sei em que situações os vírus } \\
\text { podem ser benéficos ao ser humano. } \\
\text { (A2, A3Q1) }\end{array}$ \\
\hline
\end{tabular}

Fonte: Dados da pesquisa.

Nessa categoria se observa que ao responderem a avaliação diagnóstica inicial (Questionário 1) os alunos apresentaram noções equivocadas ou incompletas sobre os vírus em relação aos recentes estudos da Microbiologia. Nota-se que A3 confundiu vírus com bactérias e, com isso, justificou a causa de doenças; já A2 tratou os vírus como a própria doença e não como agentes causadores de doenças; o participante A5 falou dos vírus como agentes deletérios.

Os alunos também consideram as bactérias menores que os vírus, como evidenciado no excerto de A4, A5Q1, ou alegaram não possuir ideia de comparação do tamanho entre tais elementos (vírus e bactérias), conforme a transcrição de A1Q1.

Todavia, ao contrário desses registros, em Trabulsi e Alterthum (2015) se encontra que os vírus são agentes patogênicos inclusive de bactérias, além de outros sistemas biológicos, demandando um tamanho menor em escala. Como dito anteriormente, os vírus estão classificados entre os menores agentes infecciosos conhecidos, medindo entre 12 a $400 \eta \mathrm{m}$, enquanto as bactérias medem em torno de $1000 \mathrm{\eta m}$ (Staphylococcus) (TRABULSI; ALTERTHUM, 2015).

Na subcategoria Constituição estrutural básica dos vírus, os discentes A1, A3, A5 e A6 afirmaram que os vírus apresentam composição celular. Já o aluno A2, ao ser questionado sobre constituição dos vírus foi solícito em responder que não sabia. No entanto, A4 apresentou a concepção de vírus associada com 'coisas ruins', que se juntariam para formá-lo. Essas são noções distantes da literatura microbiológica atual, como visto em Tortora, Funke e Case (2012), quanto às propriedades estruturais dessas partículas.

Quanto ao local (ambiente) no qual poderiam estar os vírus, os alunos A1 e A2 apresentaram a ideia de que "podem ser encontrados perto de sujeiras" (A1, A2Q1). O conhecimento popular de vírus associado com doenças também esteve presente nas falas dos alunos A1 e A3, que para combatê-los alegaram se valer de chás e remédios; e na crença de que o ser humano pode vir a produzir veneno para ratos com o uso de vírus (A1Q1).

Desse modo, frente às respostas obtidas no questionário 1 $\left(1^{\circ} \mathrm{MP}\right)$, evidencia-se que os alunos apresentaram concepções prévias amplamente ligadas ao conhecimento popular ou idiossincrático. Contudo, segundo as DCE do Paraná, essas noções devem ser valorizadas pelo professor e tomadas como ponto de partida para formação de conceitos científicos de cada estudante, em tempos distintos (PARANÁ, 2008).

Neste caso, a valorização das concepções alternativas dos alunos ocorreu mediante o incentivo à verbalização e ao registro de suas ideias prévias sobre o tema abordado. Com base nessa evidenciação, passa-se a reorganizar todo o planejamento didático das atividades seguintes, reconhecendo nas ideias prévias dos alunos os pontos de partida para o trabalho com noções científicas atuais.

Mediante uma condução didática adequada, é necessário trabalhar o tema a partir de estudos científicos recentes (com a devida adequação pedagógica e apoio de materiais didáticos) para ampliar o conhecimento dos alunos no sentido de aproximá-los das explicações microbiológicas atuais para o conhecimento dos vírus e suas implicações para os sistemas biológicos.

Dando continuidade à análise se percebe que os alunos denotaram, em suas falas, noções generalizadas acerca do vírus, como pode ser observado no Quadro 2, que constituiu a Categoria Noções incompletas em relação à Microbiologia recente.

Quadro 2 - Categorias efetivadas

Categoria II - Noções incompletas em relação à Microbiologia recente

\begin{tabular}{|l|l|}
\hline $\begin{array}{l}\text { Subcategoria: } \\
\text { noções do que } \\
\text { seja vírus }\end{array}$ & $\begin{array}{l}\text { É uma coisa que consegue contaminar um } \\
\text { ser humano. (A4Q1) }\end{array}$ \\
\hline $\begin{array}{l}\text { Subcategoria: } \\
\text { ambientes dos } \\
\text { vírus }\end{array}$ & $\begin{array}{l}\text { Os vírus podem ser encontrados em lugares } \\
\text { Os vírus podem ser encontrados em todo } \\
\text { lugar, no ar, nos objetos... (A3Q1) } \\
\text { vivos. (A5Q1) }\end{array}$ \\
$\begin{array}{l}\text { Os vírus podem ser encontrados no oxigênio } \\
\text { (ar), água ou até mesmo em alimentos. } \\
\text { (A6Q1) }\end{array}$ \\
$\begin{array}{l}\text { Subcategoria: } \\
\text { meios de } \\
\text { combate aos } \\
\text { vírus }\end{array}$ & $\begin{array}{l}\text { A melhor maneira de combate aos vírus é } \\
\text { A melhor maneira de combater os vírus é se } \\
\text { cuidando. (A4Q1) } \\
\text { A melhor maneira de combate aos vírus é } \\
\text { lavando as mãos, os alimentos antes de } \\
\text { comer, ter mais higiene. (A6Q1) }\end{array}$ \\
\hline
\end{tabular}

Fonte: Dados da pesquisa.

Observa-se nessa categoria os pareceres generalistas dos alunos ao conceituarem vírus como "uma coisa que consegue contaminar um ser humano" (A4Q1). Nesse excerto textual em específico, embora o aluno tenha concebido vírus como 
um agente infeccioso ao ser humano, não fez menção a outros seres vivos. Constata-se essa mesma ideia generalista nas respostas quanto aos ambientes nos quais os vírus poderiam estar, ao relacionarem "lugares contaminados" (A4Q1), "em todo lugar, no ar, nos objetos" (A3Q1), "nos seres vivos" (A5Q1), “ou até mesmo em alimentos" (A6Q1).

Quando questionados sobre a melhor maneira de combater ou se prevenir dos vírus, os educandos fizeram associação somente com hábitos de higiene (A2, A6Q1), ou ainda, "se cuidando" (A4Q1), sem maiores esclarecimentos.

Sobre essas respostas, Pozo e Crespo (2009) esclarecem que os alunos, como qualquer um, interpretam qualquer situação ou conceito que lhes for apresentado, a partir de seus conhecimentos prévios, sua física, química, biologia pessoal ou intuitiva. Também assinalam que para determinadas situações concretas, rotineiras e simples, o conhecimento cotidiano por ter "menor custo cognitivo" é mais previsível que o científico, portanto empregado com mais frequência (POZO; CRESPO, 2009). Isso posto, tem-se como suposição que as explicações generalistas dadas pelos alunos foram decorrentes da gênese heurística da busca por respostas para a professora.

No Quadro 3 é apresentada uma compilação das transcrições textuais, que compuseram a terceira e a última categoria de análise.

Quadro 3 - Categorias efetivadas Categoria III - Noções próximas à Microbiologia recente

Vírus é um micro-organismo que pode trazer doenças aos humanos. (A6Q1)

$\mathrm{O}$ vírus é um parasita que é feito de uma cápsula de proteína e material genético. (A1Q2)

Os vírus é um micro-organismo que não tem célula. (A2Q2)

Subcategoria: É um ser que pode causar doenças ou dele fazer noções do que vacinas. (A6Q2)

$\mathrm{O}$ vírus é um micro-organismo. (A4Q2)

Os vírus não são formados por células, não respiram, nem se alimentam como os outros seres. Mas, quando estão no interior de uma célula, como a bactéria, eles conseguem se reproduzir. (A5Q2)

É um ser que pode causar doenças ou dele fazer vacinas. (A6Q2)

Subcategoria:

comparação

quanto ao

tamanho

de vírus e

bactérias

Subcategoria:

constituição

estrutural

básica dos

vírus

Em relação à bactéria, o vírus é menor. ( $\mathrm{A} 1, \mathrm{~A} 2$, A3, A4, A5, A6Q2)

$\mathrm{O}$ vírus é formado por cápsula de proteína e material genético. (A1, A2, A6Q2)

$\mathrm{O}$ vírus pode ser encontrado no ar, em multidão... (A1Q2)

Subcategoria: ambientes dos vírus

$\mathrm{O}$ vírus pode ser encontrado no ar, no mosquito, em plantas, no ser humano. (A2Q2)

$\mathrm{O}$ vírus pode ser encontrado em todo lugar, no

ar é um lugar que se pode encontrar. (A3Q2)

$\mathrm{O}$ vírus pode ser encontrado no ar, água, plantas (A6Q2)

\begin{tabular}{|l|l|}
\hline $\begin{array}{l}\text { Subcategoria: } \\
\text { meios de } \\
\text { combate aos } \\
\text { vírus }\end{array}$ & $\begin{array}{l}\text { A6Q2) } \\
\text { Toma-se vacina para 'transmitir' anticorpos } \\
\text { É importante ir ao médico para combater os } \\
\text { vírus. (A4Q2) } \\
\text { São os anticorpos que combatem o vírus por } \\
\text { meio da vacina. (A5Q2) } \\
\text { A melhor maneira de combater os vírus são as } \\
\text { vacinas. (A5Q1) }\end{array}$ \\
\hline $\begin{array}{l}\text { Os vírus podem ser usados pelo ser humano } \\
\text { para fazer vacina, para futuramente curar o } \\
\text { câncer e para matar as lagartas e outros seres } \\
\text { que devoram a plantação. (A1Q2) } \\
\text { Simo benéfico os vírus podem ser usados pelo ser } \\
\text { dos vírus pelo } \\
\text { ser humanano de forma benéfica para fazer vacina, } \\
\text { no combate de pragas. (A3, A4, A5, A6Q2) } \\
\text { Sim, o vírus pode ser usado pelo ser homem } \\
\text { para combater o câncer de mama e também a } \\
\text { lagarta que come a folha de mandioca. (A2Q2) }\end{array}$ \\
\hline
\end{tabular}

Fonte: Dados da pesquisa.

Como se percebe nos excertos acima, os alunos A5 e A6 desde o questionário inicial apresentavam noções mais próximas à Microbiologia recente. Para A5, “a melhor maneira de combater os vírus são as vacinas" (A5Q1), enquanto A6 respondeu que "vírus é um micro-organismo que pode trazer doenças aos humanos" (A6Q1). As demais respostas desse quadro estão relacionadas ao questionário final (Q2), ou seja, aquele que integra o $3^{\circ}$ Momento da sequência de atividades.

Para além de uma concepção positivista de ensino acerca de vírus, ou seja, a aprendizagem como uma "cópia fiel" do conhecimento científico ou uma espécie de "mantra" que os alunos devessem repetir, segundo Pozo e Crespo (2009), ao se perguntar o que é vírus, foi oportunizado a cada aluno transcrever o que assimilou, conforme a subcategoria Noções do que seja vírus. Nessa subcategoria, os discentes empregaram terminologias específicas como "Ser não vivo parasitário" (A3Q2), "Um micro-organismo que não tem célula (A2Q2), "Um ser que pode causar doenças ou dele fazer vacinas" (A6Q2), que dantes empregavam como "coisa", conforme vimos na subcategoria antecedente (A4Q1).

Outro aspecto considerado relevante compreendeu a transcrição do aluno A5 no Questionário 2. Ao conceituar vírus, escreveu: "Os vírus não são formados por células, não respiram, nem se alimentam como os outros seres. Mas, quando estão no interior de uma célula, como a bactéria, eles conseguem se reproduzir" (A5Q2). O mesmo aluno, no questionário 1 (avaliação diagnóstica inicial), escreveu sobre os vírus como "coisa ruim que se espalha" (A5Q1).

$\mathrm{Na}$ subcategoria Comparação quanto ao tamanho de vírus e bactérias, os seis alunos analisados evidenciaram, por meio da intervenção de ensino, assimilar que vírus (em sua maioria) são menores que bactérias. A mesma coisa foi percebida na subcategoria Constituição estrutural básica dos vírus, ao associarem material genético e cápsula de proteína à composição viral.

Quanto aos ambientes nos quais os vírus poderiam ser 
encontrados, destaca-se a transcrição de A2 ao responder que "O vírus pode ser encontrado no ar, no mosquito, em plantas, no ser humano" (A2Q2) que vem ao encontro da literatura específica acerca do conteúdo abordado.

$\mathrm{Na}$ subcategoria Meios de combate aos vírus, pelas análises dos excertos textuais foi possível perceber que os alunos utilizaram terminologias específicas como anticorpos (A2, A5Q2) para explicar os elementos, que protegem o corpo dos parasitas, assim como a compreensão de que as vacinas são meios de combate aos vírus, como no caso de "São os anticorpos que combatem o vírus por meio da vacina" (A5Q2).

Essa noção encontra apoio em pesquisas da área de Ensino relacionadas à contextualização das disciplinas escolares com assuntos do cotidiano do aprendiz (vacinas), gerando evidências da promoção de uma aprendizagem efetiva e com significados (KATO; KAWASAKI, 2011; DELIZOICOV; ANGOTTI; PERNAMBUCO, 2009).

Por fim, na subcategoria Uso benéfico dos vírus pelo ser humano, os seis alunos cujos questionários (avaliações) foram analisados, mostraram maior conhecimento do emprego de determinados vírus em vacinas, do combate de pragas na agricultura e estudos relacionados às células tumorais. A título de exemplo, traz-se o excerto de A1Q2: “Os vírus podem ser usados pelo ser humano para fazer vacina, para futuramente curar o câncer e para matar as lagartas e outros seres que devoram a plantação".

Nesse sentido, retoma-se Krasilchik (2005) que alertava para o fato de que a análise de fenômenos biotecnológicos serve para diminuir a divisão entre a escola e o mundo, em que os estudantes vivem, ao constatarem as relações entre a pesquisa científica e a produção industrial ou a tecnologia.

Com isso, a percepção foi de que ao final do desenvolvimento desta proposta pedagógica, os vilões (vírus) também passaram a ser vistos como elementos favoráveis à vida e que muitas pesquisas importantes são realizadas com essas partículas com vistas à melhoria da qualidade de vida das pessoas. A seguir, finaliza-se o artigo com algumas considerações sobre o percurso investigativo deste estudo.

\section{Conclusão}

Apresentam-se os resultados de uma pesquisa que buscou respostas para a seguinte questão norteadora: $u$ ma sequência pautada na relação CTSA e organizada nos 3MP pode favorecer a aprendizagem do conteúdo vírus no âmbito do Ensino Fundamental - anos finais?

Assim, uma proposta de ensino foi desenvolvida e aplicada em uma turma do $7^{\circ}$ ano do Ensino Fundamental anos finais, de um colégio público paranaense, na disciplina de Ciências. Essa proposta foi pautada nos 3MP e buscou, de modo contextual e dialógico, problematizar o tema vírus relacionando-o a vacinas e noções de Biotecnologia, na perspectiva CTSA, valorizando os conhecimentos prévios dos alunos $\left(1^{\circ} \mathrm{MP}\right)$.

Frente à insuficiência de argumentos baseados em seus conhecimentos prévios, os alunos foram provocados para a busca de maiores esclarecimentos ( $\left.2^{\circ} \mathrm{MP}\right)$. Para tanto, como forma de organização do conhecimento, recorreu-se ao uso de vídeos, de textos informativos, de livro didático e de explicações com apoio do quadro de giz.

$\mathrm{Na}$ Aplicação do Conhecimento ( $\left.3^{\circ} \mathrm{MP}\right)$ foram elaboradas, pelos alunos histórias em quadrinhos sobre vírus, vacinas, sistema imunológico e construídos modelos didáticos com materiais alternativos. Dessa forma, tendo em vista a proposta de ensino pautada nos 3MP, evidencia-se que ao final da aplicação das atividades, as noções dos alunos foram mais próximas aos conhecimentos recentes da Microbiologia (sobre vírus).

Sustenta-se essa evidenciação a partir da presença de respostas mais elaboradas nos excertos textuais analisados do questionário 2 (avaliação final), nos quais foram detectadas maior clareza e emprego de termos pertinentemente aplicados, como: "parasita", "anticorpos", "micro-organismos" em contextos explicativos adequados, diferentemente das respostas obtidas no questionário 1 (avaliação diagnóstica inicial).

As categorias extraídas do referencial teórico e efetivadas a partir da Análise Textual Discursiva realizada reforçaram a noção de que a proposta trouxe contribuições.

Finalmente, a compreensão dos alunos frente à utilização de determinados vírus em vacinas, em terapia gênica e controle de pragas na agricultura, foi considerada satisfatória, conforme os relatos analisados. De modo geral, argumentase que a proposta foi contributiva para o entendimento da temática vírus, por parte dos alunos participantes, com o apoio da tendência metodológica dos 3MP, que organizou as ações em sala de aula e possibilitou que a perspectiva CTSA pudesse ser desenvolvida frente ao tema e às atividades sugeridas.

Como desdobramento, fica a sugestão de que novas propostas possam ser empreendidas, com temáticas variadas, para o ensino efetivo e contributivo das disciplinas escolares em favor da educação científica dos estudantes.

\section{Referências}

BRASIL.Ministério da Saúde. Informe técnico sobre a vacina papilomavírus humano (HPV) na atenção básica. Brasília: MS, 2014.

BOGDAN, R.; BIKLEN, S. Investigação qualitativa em educação: uma introdução à teoria e aos métodos. Portugal: Porto, 1994.

CHASSOT, A. Alfabetização científica: uma possibilidade para a inclusão social. Rev. Bras. Educ., n.26, p.89-100, 2003.

CHASSOT, A. Alfabetização científica: questões e desafios para a educação. Ijuí: UNIJUI, 2017.

DELIZOICOV, D. Concepção problematizadora do ensino de ciências na educação formal: relato e análise de uma prática educacional na Guiné Bissau. São Paulo: Universidade de São Paulo, 1982.

DELIZOICOV, D. Ensino de física e a concepção freireana de educação. Rev. Ensino Fís., v.5, n.2, p.85-98, 1983. 
DELIZOICOV, D.; ANGOTTI, J.A.; PERNAMBUCO, M.M. Ensino de ciências: fundamentos e métodos. São Paulo: Cortez, 2009.

GUERRA, I.C. Pesquisa qualitativa e análise de conteúdo: sentido e formas de uso. Portugal: Principia, 2006

KATO, D.S.; KAWASAKI, C.S. As concepções de contextualização do ensino em documentos curriculares oficiais e de professores de ciências. Ciênc. Educ., v.17, n.1, p.35-50, 2011

KRASILCHIK, M. Prática de ensino de biologia. São Paulo: USP, 2005.

MARCHESAN, M.R.; KUHN, M.C. Alfabetização científica e tecnológica na formação do cidadão. Thema, v.13, n.3, p.118129, 2016.

MEDEIROS, F.N.S. A influência da escolaridade sobre as percepções de clonagem e células-tronco. Rev. Assoc. Bras. Ensino Biol., n.1, 2007.

MORAES, R.; GALIAZZI, M.C. Análise textual discursiva. Ijuí: Unijuí, 2011.

MUENCHEN, C.; DELIZOICOV, D. Os três momentos pedagógicos e o contexto de produção do livro "Física". Ciênc. Educ., v.20, n.3, p.617-638, 2014.

PARANÁ, Secretaria de Estado da Educação. Diretrizes Curriculares Orientadoras da Educação Básica do Estado do Paraná. Ciências. Curitiba: SEED, 2008.

PALACIOS, E.M.G. et al. Introdução aos estudos CTS. Espanha: OEI, 2003.

PIRES, A. De quelques enjeux épistémologiques d'úne méthodologie générale pour les sciences socieales. In: DANS POUPART, J. et al. La recherche qualitative, enjeux épistémologiques et méthodologiques. Canadá: Gaëtan Morin, 1997. p.3-54.

POZO, J.I.; CRESPO, M.Á.G. A aprendizagem e o ensino de
Ciências: do conhecimento cotidiano ao conhecimento científico. Porto Alegre: Artmed, 2009.

PRAIA, J.F. Contributo para uma leitura possível de um percurso profissional. In: CARVALHO, A.M.P.C.; CACHAPUZ, A.F.; GIL-PÉREZ, D. O ensino das ciências como compromisso científico e social. São Paulo: Cortez, 2012. p. 53-73.

QUINATO, G.A.C. Educação científica, CTSA e ensino de física: contribuições ao aperfeiçoamento de situações de aprendizagem sobre entropia e degradação de energia. Bauru: Universidade Estadual Paulista Júlio de Mesquita Filho, 2013.

ROTHBERG, D.; QUINATO, G.A.C. Ensino de ciências e CTS: contribuições ao aperfeiçoamento de situações de aprendizagem sobre entropia e degradação de energia. Alexandria, v.9, n.1, p.179-206, 2016.

SASSERON, L.H.; CARVALHO, A.M.P. Almejando a alfabetização científica no ensino fundamental: a proposição e a procura de indicadores do processo. Investig. Ensino Ciênc., v.13, n.3, p.333-352, 2008 .

SILVA, L.F.; CARVALHO, L.M. A temática ambiental e o processo educativo: o ensino de Física a partir de temas controversos. Ciênc. Ensino, n.esp., 2007.

TOMA, E. H. O. Mundo nanométrico: a dimensão do novo século. São Paulo: Oficina de Textos, 2009.

TORTORA, G. J.; FUNKE, B. R.; CASE, C. L. Microbiologia. Porto Alegre: Artmed, 2012.

TRABULSI, L. R.; ALTERTHUM, F. Microbiologia. São Paulo: Atheneu, 2015.

TRIVELATO, S. F.; SILVA, R. L. F. Ensino de ciências. São Paulo: Cengage Learning, 2011.

ZUIN, V. G.; FREITAS, D. A utilização de temas controversos: estudo de caso na formação de licenciandos numa abordagem CTSA. Ciênc. Ensino, v. 1, n. 2, 2007. 